\title{
Machine Learning Aided Tracking Analysis of Haze Pollution and Regional Heterogeneity
}

\author{
Fangfang Gu${ }^{1}$, Keshen Jiang ${ }^{2}$, Fangdong $\mathrm{Cao}^{3^{*}}$ \\ ${ }^{1}$ College of Economics and Management \\ Nanjing University of Aeronautics and Astronautics,Nanjing, China \\ [e-mail: gff_0817@163.com] \\ ${ }^{2}$ College of Economics and Management \\ Nanjing University of Aeronautics and Astronautics,Nanjing, China \\ [e-mail: jiangksh@126.com] \\ ${ }^{3}$ School of Geography \\ Nanjing Normal University,Nanjing, China \\ [e-mail: caofangdong@njnu.edu.cn] \\ *Corresponding author: Fangdong Cao
}

Received March 18, 2021; revised May 5, 2021; accepted May 18, 2021; published June 30, 2021

\begin{abstract}
Not only can air pollution reduce the overall competitiveness of tourist destinations, but also changes tourists' travel decisions, thereby affecting the tourism flows. The study presents a machine learning method to analyze how the haze pollution puts spatial effect on tourism flows in China from 2001 to 2018, and reveals the regional differences in heterogeneity among eastern, central, and western China. Our investigation reveals three interesting observations. First, the Environmental Kuznets Curve of the impact of haze pollution on tourism flows is not significant. In the eastern and western regions, the interaction between haze pollution and domestic tourism flows as well as inbound tourism flows shows an inverted U-shaped curve respectively. Second, there is an significantly positive spillover effect of tourism flows in all of the eastern, central, and western regions. As to the intensity of spillover, domestic tourism flows is higher than that of the inbound tourism flows. Both of the above figures are greatest in the eastern. Third, the Chinese haze pollution mainly reduces the inbound tourism flows, and only imposes significantly negative direct effects on the domestic tourism flows in the central region. In the central and eastern regions, significantly negative direct effects and spillover effects are exerted on inbound tourism.
\end{abstract}

Keywords: Haze Pollution, Machine Learning, Tourism Flows, Spatial Effect, Regional Heterogeneity 


\section{Introduction}

China's urbanization rate and GDP per capita have been increasing along with the rapid development of society. However, following the technological progress and the development of large-scale industrial production, environmental problems have become increasingly prominent, especially air pollution [1-3]. Although haze, as a global problem, is not a "patent" of any country or region, large-scale haze weather with PM2.5 as the primary pollutant, which happens frequently in China in recent years, has attracted widespread attention home and abroad. The persistent aggravation of regional haze pollution and the thorough media coverage deeply damages the international tourism images and urban tourism attractiveness of many cities [4-8]. The municipal unit is an important spatial vehicle for tourists' haze risk perception and selection of travel destinations at the regional scale. Hence, conducting research on the haze pollution's impact on tourism from the municipal level has essential significance.

The spillover effect is an economic term often mentioned in many studies. It refers to an element in an area that not only affects the area, but also indirectly affects related elements in other areas nearby. Previous studies found that both haze and tourism flows can be spatially dispersed, affecting local and adjacent areas and creating spatial spillover effects [9-12]. Air pollution slows down the development of tourism [13-16], but it is unclear whether this negative effect is significant. For example, in the practice of tourism development in mainland China, there is no significant evidence that haze pollution is negatively correlated with local tourism development. As an industrial cluster, eastern China has more serious haze pollution and prosperous tourism development inversely, while western China has relatively lighter haze pollution and lower levels of tourism development. The rapid development of industry and agriculture has brought some drawbacks, such as the decline in air quality. Recently, there have been frequent occurrences of haze pollution weather, but the tourist quantity (especially domestic tourists) has also grown rapidly. Therefore, how haze pollution impacts urban tourism and what's the exact relationship between the two factors remain to be clarified, and urgent attention should be paid to the effect of haze on tourism flows in urban travel destinations.

\section{Literature Review}

Haze pollution is a kind of mixed air pollution that is mainly caused by industrial waste gas, coal smoke, and vehicle exhaust emissions [17-19]. PM2.5 (particulate matter with aerodynamic diameter $\leq 2.5 \mu \mathrm{m}$ in ambient air) is identified as the primary pollutant of haze which can be directly inhaled into the lungs [20,21]. Haze poses serious harm to human health, which increases the incidence of respiratory tract, cardiovascular, cerebrovascular diseases, and nervous system diseases. Existing studies mainly focus on the composition and sources of haze [22,23], its distribution characteristics [24,25], and its influence, etc. Because haze will spread with the wind, it will affect other regions and produce a spatial spillover effect, which has attracted the attention of many scholars in recent years [26-29].

Human tourism activities are greatly affected by weather and climate due to their long-term exposure to air [30-32]. Suitable climate and good weather will increase the comprehensive competitiveness of tourist destinations, improve the images, and pull up the rapid and healthy development of the tourism industry [33]. On the contrary, bad weather not only causes serious harm to tourists' health [14], but also increases the risk perception of tourists [15], leading to declining quality of tourism experience and causing tourists to change or even cancel their 
itineraries [34]. Up to now, the previous literature mainly explored the impact of haze pollution on tourism from two aspects. First is the impact on tourism development [35]. Most of the studies use the arrival of tourists as the measurement standard of tourism development [36]. Based on Poisson Regression Analysis, the impact of haze pollution on the number of tourists and the economic development of the tourism industry is empirically illustrated in Brunei Darussalam [37]. Taking Beijing as an example, it is found that air pollution had negative effects on tourist arrivals in the long-run, but not in the short-run [38]. It is also confirmed that haze pollution and inbound tourism growth in mid-eastern China have apparent spatial autocorrelation and significant spatial spillover effects [39]. On the other hand, haze pollution has impact on tourists' perception. It is suggested that international tourists did not have a strong perception of Hong Kong's air quality, and they were willing to fund environmental improvement, which was conducive to promote the growth of tourism flows [6]. Some researchers used questionnaire survey to discover the impact of haze on Beijing residents' risk perception and experience of tourism [13]. The study found that haze pollution had a significant impact on the image of Beijing, and potential tourists were constantly decreasing. Others proposed a spatial analytical framework to explore tourist experiences from geotagged social media data in Beijing in 2013 [40]. They investigated tourists who reported fewer positive sentiments and more health issues due to increasing air pollution.

Admittedly, natural disasters represented by haze weather have brought significant negative impacts on tourism, and such negative impacts have regional heterogeneity. However, the current academic research on haze pollution and tourism flows is still at a relatively isolated level, and there is a lack of comparative studies from the two aspects of regional differences and domestic and inbound tourism flows. Therefore, our research attempts to explain the effects and regional heterogeneity characteristics of haze on tourism flows in China, including domestic and inbound tourism flows, from the perspective of cities from 2001 to 2018, so as to fill in gaps in the research on the impact of haze on urban tourism and provide the tourism industry with policy suggestions.

\section{Methodology}

\subsection{Methodology}

Spatial econometric models are regression models that are dealing with spatial dependence and spatial heterogeneity in the system of computer-aided learning methods. Spatial Lag Model (SLM), Spatial Error Model (SEM) and Spatial Durbin Model (SDM) are the most commonly used models.

SDM has a more general form than SEM and SLM. SEM includes the interaction effect among the random error terms of the explanatory variables, and SLM includes the endogenous spatial interaction effect of the explained variables, while SDM encompasses the spatial dependence effect of both the explanatory and explained variables, taking both endogenous and exogenous interaction effects into consideration. Therefore, SDM is constructed in this study to estimate the spatial dependence effect of explanatory variables such as haze pollution and the explained variable of tourism flows (including domestic and inbound tourism flows), and then to estimate the direct and indirect effects of explanatory variables such as haze pollution on the explained variable of tourism flows $[41,42]$. SDM is formulated as follows: 


$$
Y=\rho W Y+\beta X+\varphi W X+\varepsilon, \varepsilon \sim N\left(0, \delta^{2}\right)
$$

where $\mathrm{Y}$ is the $\mathrm{n} \times$ 1-dimensional vector matrix of explained variables. If there are $\mathrm{k}$ explained variables, $\mathrm{X}$ is the $\mathrm{n} \times \mathrm{k}$-dimensional matrix of explanatory variables. $\rho$ is the spatial lag coefficient of the explained variables, i.e., the coefficient of the endogenous interaction effect. $\beta$ is the regression coefficient of the explanatory variables. $W$ is the spatial weight matrix constructed based on the proximity criterion. $\varphi$ is the coefficient of the spatial interaction effect of the explanatory variables on the explained variables. $\varepsilon$ is the random error term that is independent and identically distributed. It can be found that: when $\varphi=0$ and $\rho \neq 0$, the SDM is simplified to the SLM; when $\varphi^{+} \rho \beta=0$, SDM is simplified to the SEM model. The significance level of $\varphi$ determines the strength of the spatial interaction among the explanatory variables $[11,41,42]$.

\subsection{Indicator Selection and Data Sources}

In the regression model, the explained variable is tourism flows, which is characterized by the arrival of tourists to a city in one year, including domestic and inbound tourism. The explanatory variable is the concentration of haze, which is characterized by the concentration of PM2.5 (in $\left.\mu \mathrm{g} / \mathrm{m}^{3}\right)$. Considering that the logarithmic treatment of data can eliminate the effect of variance, the results of logarithmic treatment of data for tourism flows, domestic tourism flows, inbound tourism flows, and core explanatory variable haze pollution are noted as LnTf, LnDtf, LnItf, and LnPm respectively. The changing of tourism flows is subject to the combined effect of many elements. In addition to the influence of haze, resource endowment, market development, infrastructure, and the degree of opening up also play an important role in tourism flows. Therefore, in this paper, factors such as economic development, tourism resources, infrastructure, transportation location, market size, and external linkage that affect tourism flows in municipal units are included in the model as control variables $[14,37,39]$. Among them, (1) the economic development factor (Eco) is a prerequisite and important foundation for tourism development, and GDP per capita (10,000 yuan) is selected to represent it. The GDP index is deflated with 2001 as the base year. (2) Tourism resource endowment (Res) characterizes tourism development and the ability to attract tourists, and the number of tourist attractions above 4A level in each city is selected. (3) Transportation location factor (Tra) is a prerequisite for tourism development, and the indicator of road network density is used to characterize the regional transportation status. (4) Tourism infrastructure (Inf) is a foundation for the development of urban tourism, which reflects the city's ability to receive users. Accommodation facilities and reception facilities are important content of Inf. Therefore, star-rated hotels and travel agencies are selected. (5) The market size factor (Mar) characterizes the actual and potential source markets for tourism and is expressed by using the indicator of urban population density, which is not included in the econometric model of the influence of haze pollution on inbound tourism flows. (6) The external linkage (FDI) characterizes the attractiveness to the inbound tourism market, and the amount of actually utilized foreign direct investment is selected. This indicator is not included in the econometric model of the influence of haze pollution on domestic tourism flows.

The statistical data of control variables selected for this paper is mainly obtained from China City Statistical Yearbook, China Regional Economic Statistical Yearbook, as well as the provincial and prefecture-level city statistical yearbooks, national development statistical 
bulletins, and official tourism websites. The haze pollution data are characterized by the annual average PM2.5 concentration $(\mu \mathrm{g} / \mathrm{m} 3)$ data of each city. The data is mainly obtained from the Atmospheric Composition Analysis Group (ACAG) of Dalhousie University, which were raster data estimated by using NASA satellites and a combination of data from ground-based monitoring stations. The data were parsed using ArcGIS and can be used directly at the city levels (http://fizz.phys.dal.ca/ atmos/martin/?page_id=140). Given the availability of data, our research selects 342 cities in China as the research objects, including 101 cities in the eastern, 122 cities in the middle, and 119 cities in the western.

\section{Performance Analysis of Haze Pollution on Urban Tourism Flows}

\subsection{Correlation Feature Analysis}

The Environmental Kuznets Curve (EKC) is the most widely used mathematical model to verify the synergistic relationship between economic growth and environmental issues [43]. In order to verify whether there is a phenomenon similar to the EKC hypothesis in the economic development process between haze pollution and tourism flows, the time series data of PM2.5 concentration and tourism flows of China as a whole as well as detailed data of cities in the eastern, central, and western regions from 2001 to 2018 are used to draw scatter plots of haze pollution and tourism flows, and the relationship between variables is modeled with the help of quadratic polynomial fitting (Fig. 1 and Fig. 2). The $\mathrm{R}^{2}$ values of the quadratic polynomial fit between haze pollution and domestic tourism flows and inbound tourism flows are 0.0887 and 0.0078 respectively. The inverted U-shaped curve relationship between haze pollution and domestic tourism flows is present only in the eastern and western regions, while the inverted U-shaped curve relationship between haze pollution and inbound tourism flows is present only in the western region, which is not significant, and in the central region, there is a weak U-shaped curve relationship. In general, the Environmental Kuznets Curve between haze pollution and tourism flows is not significant, and there are some inverted U-shaped curve relationships between haze pollution and domestic and inbound tourism flows in the eastern and western regions.
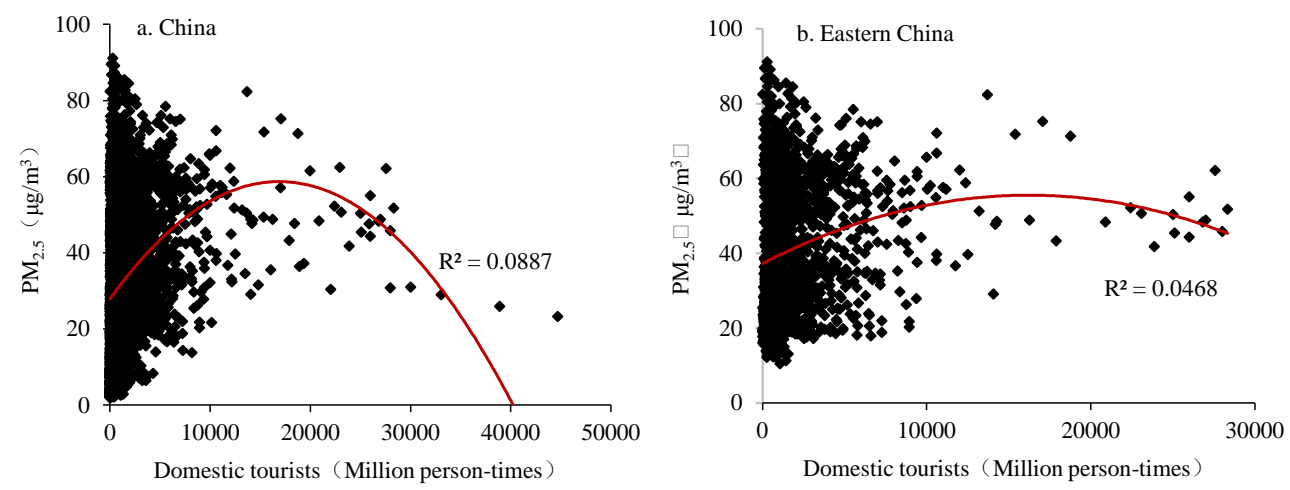

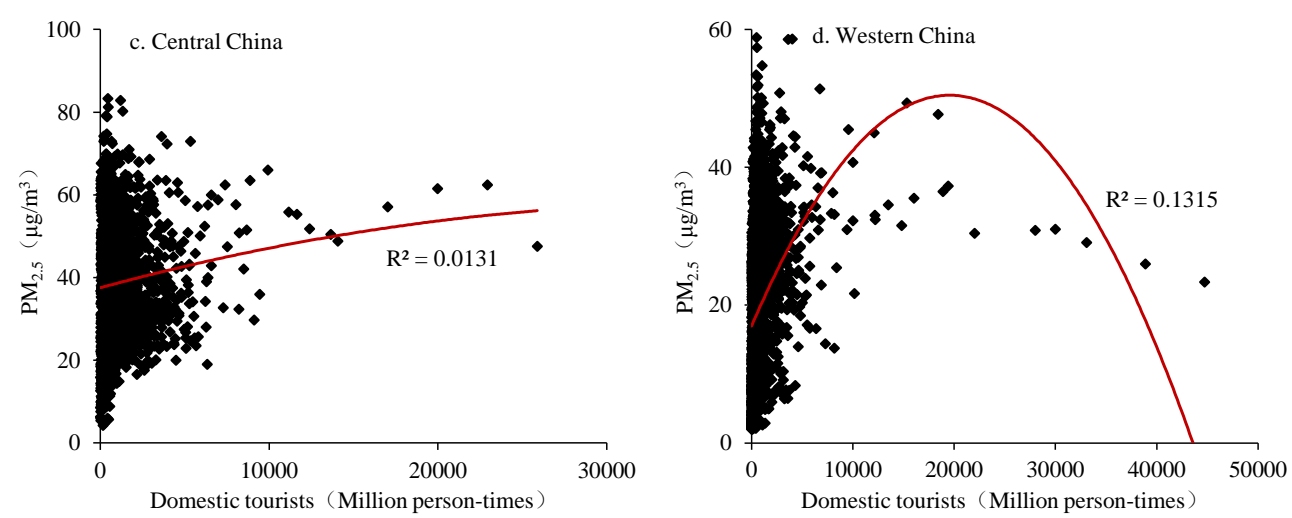

Fig. 1. Scatter plot of haze pollution and domestic tourism flows
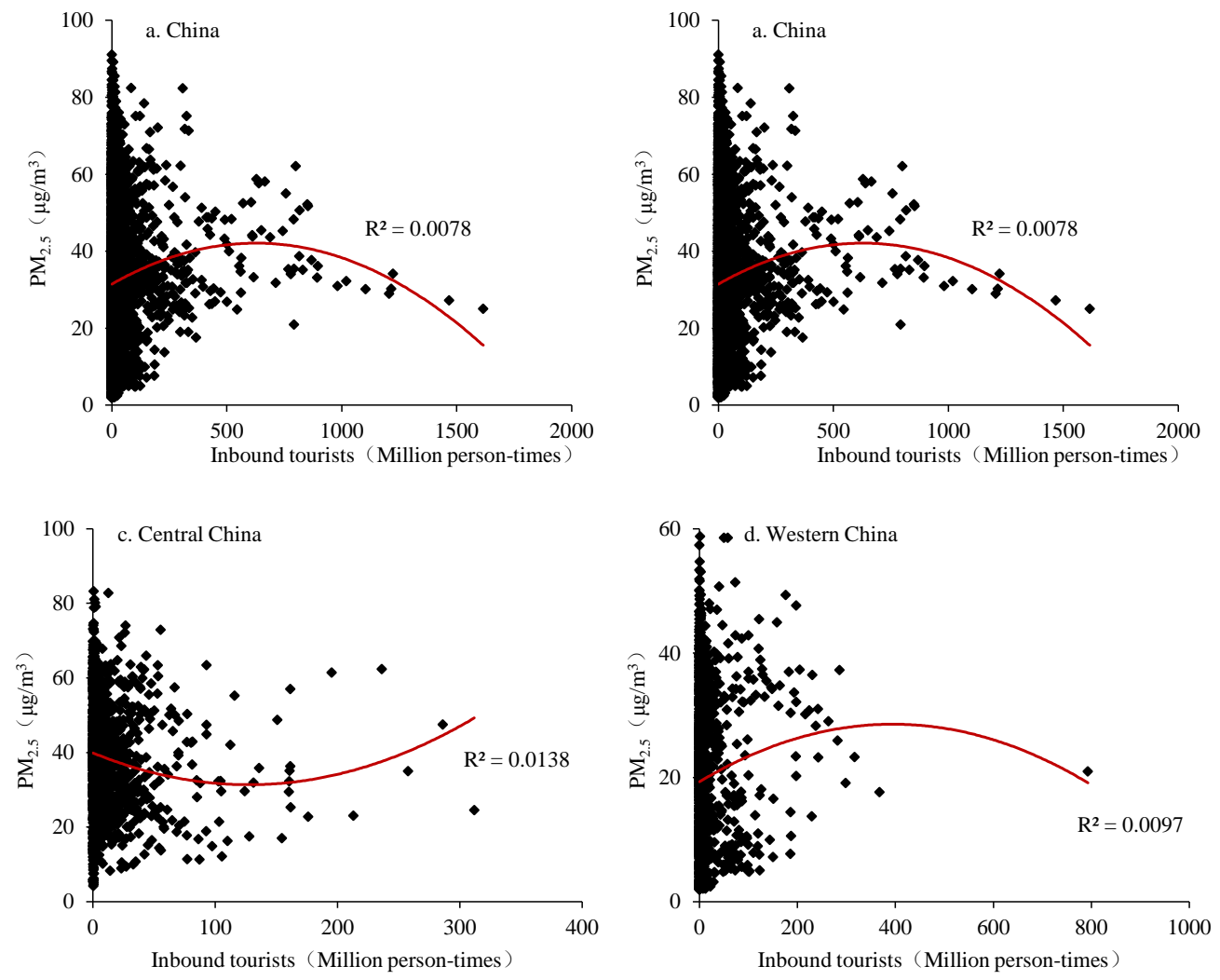

Fig. 2. Scatter plot of haze pollution and inbound tourism flow

\subsection{Analysis of the Estimation Results}

The results of the spatial correlation test indicates that haze pollution and tourism flows in Chinese cities have essential spatial dependence. Hence, the spatial element cannot be neglected when studying their relationship. Before model estimation, a (Robust) LM test is required (Table 1). According to Table 1, several test methods of the econometric models of 
the effects of haze pollution on domestic tourism flows and inbound tourism flows all pass the significance level test of 0.01, making it difficult to determine which is optimal among SEM, SLM, and SDM. Moreover, Walds and Likelihood Ratio (LR) tests are used to determine whether SDM is able to be reduced to SEM and SLM $[41,42,44]$. Both Walds and LR statistics in Table 1 pass at least the significance level test of 0.05 , indicating that SDM cannot be simplified to SLM or SEM. SDM is therefore the optimal spatial econometric model. For comparison, the variables are also estimated by the OLS model, SLM, and SEM, the estimation results are shown in Tables 2 and 3.

Table 1. Spatial econometric models identification test results

\begin{tabular}{ccc}
\hline Test Methods & Domestic Tourism & Inbound Tourism \\
& Flows & Flows \\
Statistics & Statistics \\
\hline LM-lag & $21.244^{* * *}$ & $18.320^{* * *}$ \\
Robust LM-lag & $16.125^{* * *}$ & $11.257^{* * *}$ \\
LM-error & $48.258^{* * *}$ & $12.689^{* * *}$ \\
Robust LM-error & $16.285^{* * *}$ & $14.218^{* * *}$ \\
Wald-spatial lag & $32.172^{* * *}$ & $22.369^{* *}$ \\
LR-spatial lag & $36.650^{* * *}$ & $25.369^{* * *}$ \\
Wald -spatial error & $42.187^{* * *}$ & $36.284^{* * *}$ \\
LR-spatial error & $39.547^{* * *}$ & $28.465^{* * *}$ \\
\hline
\end{tabular}

Note: $* * *, * *$ and $*$ represent significance at the levels of $0.01,0.05$ and 0.10 , respectively.

Table 2. OLS, SEM, SLM and SDM estimation results of the impact of haze pollution on domestic tourism flows

\begin{tabular}{ccccc}
\hline Variables & OLS & SEM & SLM & SDM \\
\hline LnPm & 0.157 & 0.169 & 0.296 & 0.258 \\
LnEco & $0.560^{* * *}$ & $0.534^{* *}$ & $0.501^{* * *}$ & $0.618^{* * *}$ \\
LnRes & $0.401^{* *}$ & $0.495^{* * *}$ & $0.396^{*}$ & $0.325^{* *}$ \\
LnTra & $0.232^{* * *}$ & $0.308^{* *}$ & $0.277^{* *}$ & $0.240^{* *}$ \\
LnInf & $0.202^{* *}$ & $0.198^{* *}$ & $0.401^{*}$ & $0.217^{* *}$ \\
LnMar & $0.656^{* * *}$ & $0.521^{* *}$ & $0.498^{* * *}$ & $0.569^{* * *}$ \\
LnFDI & - & - & - & - \\
$W \times \operatorname{Ln} P m$ & & & & 0.160
\end{tabular}




\begin{tabular}{|c|c|c|c|c|}
\hline$W \times \operatorname{Ln} E c o$ & & & & $0.271^{* *}$ \\
\hline$W \times \operatorname{Ln} R e s$ & & & & -0.169 \\
\hline$W \times \operatorname{LnTra}$ & & & & $-0.101^{* *}$ \\
\hline$W \times \operatorname{Ln} I n f$ & & & & $0.229 * *$ \\
\hline$W \times \operatorname{Ln} M a r$ & & & & $0.337 * * *$ \\
\hline$W \times \operatorname{Ln} F D I$ & & & & - \\
\hline$\rho$ & & & $0.416^{* * *}$ & $0.455^{* * *}$ \\
\hline$\lambda$ & & $0.251 * * *$ & & \\
\hline Adjusted $R^{2}$ & 0.589 & 0.829 & 0.824 & 0.898 \\
\hline Loglikelihood & 125.366 & 275.041 & 279.255 & 355.232 \\
\hline
\end{tabular}

Based on the estimation results in Tables 2 and 3, SDM is also the optimal model to explain the impact of haze pollution on domestic and inbound tourism flows. The estimation results of SEM for the effect of haze pollution on domestic and inbound tourism flows show $\lambda$ values of 0.251 and 0.360 respectively, and pass the significance level test of 0.01 , indicating that there is also a possibility of omitting explanatory variables in the regression model, and there may be more omitted explanatory variables in the regression model for the impact of haze pollution on inbound tourism flows, which are also interacted spatially. The values of spatial lag term $\rho$ in SDM on domestic and inbound tourism flows are 0.455 and 0.280 respectively, and both pass the significance level test of 0.01 , indicating that there is a significant positive spatial spillover effect for both domestic and inbound tourism flows in geographic space, and the spatial spillover intensity of domestic tourism flows is significantly higher than that of inbound tourism flows. Provided that other explanatory variables are controlled, a 1\% increase in domestic and inbound tourism flows in a neighboring municipal unit will lead to a $0.455 \%$ and $0.280 \%$ increase in the local city's domestic and inbound tourism flows respectively, that is consistent with the findings of existing studies [33] [53].

From the view of spatial interaction coefficients of the control variables, the factors of economic development, tourism infrastructure, and market scale have significant positive spatial spillover effects on domestic tourism flows, with the spatial spillover coefficients being $0.271,0.229$, and 0.337 respectively. All of them pass the significance level test of at least 0.05 . The transportation location factor has significant negative spatial spillover effect on domestic tourism flows. The spatial spillover coefficient is -0.101 and passes the significance level test of 0.05 . The spatial spillover coefficient of tourism resource endowment on domestic tourism flows is -0.169 , but it does not pass the significance level test.

The economic development factor and tourism infrastructure have significant positive spatial spillover effects on inbound tourism flows, with the coefficients being 0.204 and 0.120 respectively, and both pass the significance level test of 0.10 . The transportation location factor also has significant negative spatial spillover effects on inbound tourism flows, with a coefficient of -0.175 , which passes the significance level test of 0.10 , indicating that the improvement of local tourism transportation conditions has a shielding effect on the inbound tourism market of neighboring municipal units and accelerates its decline. The spatial spillover coefficients of tourism resource endowment and external linkage on inbound tourism flows 
are 0.108 and -0.387 respectively, which do not pass the significance level test, indicating that the improvement of local tourism resource endowment and external linkage has not yet had a negative influence on the inbound tourism market of neighboring municipal units.

Table 3. OLS, SEM, SLM and SDM estimation results of the effect of haze pollution on inbound tourism flows

\begin{tabular}{|c|c|c|c|c|}
\hline Variables & OLS & SEM & SLM & SDM \\
\hline $\mathrm{LnPm}$ & $-0.154^{*}$ & $-0.110^{*}$ & $-0.102 * *$ & $-0.109 * *$ \\
\hline $\operatorname{LnEco}$ & $0.412^{* *}$ & $0.512^{*}$ & $0.478 * *$ & $0.562 * * *$ \\
\hline LnRes & $0.298^{*}$ & 0.265 & $0.304 *$ & $0.279 *$ \\
\hline LnTra & $0.193^{*}$ & $0.107 * *$ & $0.209 * *$ & $0.118^{*}$ \\
\hline $\operatorname{Ln} I n f$ & $0.375^{* *}$ & $0.301^{* *}$ & $0.300^{*}$ & $0.295^{*}$ \\
\hline LnMar & - & - & - & - \\
\hline $\operatorname{LnFDI}$ & $0.303^{* * *}$ & $0.319 * *$ & $0.322 * * *$ & $0.469 * *$ \\
\hline$W \times \operatorname{Ln} P m$ & & & & $-0.067 *$ \\
\hline$W \times \operatorname{Ln} E c o$ & & & & $0.204 * *$ \\
\hline$W \times \operatorname{Ln} R e s$ & & & & 0.108 \\
\hline$W \times \operatorname{LnTra}$ & & & & $-0.175^{*}$ \\
\hline$W \times \operatorname{Ln} I n f$ & & & & $0.120^{*}$ \\
\hline$W \times \operatorname{LnMar}$ & & & & - \\
\hline$W \times \operatorname{Ln} F D I$ & & & & -0.387 \\
\hline$\rho$ & & & $0.301^{* * *}$ & $0.280^{* *}$ \\
\hline$\lambda$ & & $0.360^{* * *}$ & & \\
\hline Adjusted $R^{2}$ & 0.585 & 0.764 & 0.799 & 0.809 \\
\hline Loglikelihood & 198.982 & 223.027 & 236.280 & 298.064 \\
\hline
\end{tabular}

Note: ${ }^{* * *}, * *$ and $*$ represent significance at the levels of $0.01,0.05$ and 0.10 , respectively.

\subsection{Spatial Effect Decomposition}

When studying the decomposition results of the spatial impacts of haze pollution on tourism flows (Table 4), the direct and spatial spillover effects of haze pollution on domestic tourism flows are 0.229 and -0.008 respectively, which did not pass the significance test. The direct effect and spatial spillover effects of haze pollution on inbound tourism flows are -0.124 and -0.055 respectively, which pass the significance test of 0.05 . Each $1 \%$ increase in haze pollution in the local unit reduces the local inbound tourist number by $0.229 \%$, while each $1 \%$ increase in haze pollution in neighboring urban units leads to a $0.008 \%$ decrease in the local number of inbound tourists. This indicates that haze pollution mainly has bad effect on inbound tourism, rather than domestic tourism flows at present. Since haze is prone to 
agglomeration and has obvious spillover effect, haze pollution in local and neighboring areas is closely related to the local inbound tourism market, which means that for the development of inbound tourism, haze pollution must be managed through a regional joint prevention and control strategy. Otherwise, "unilateral" efforts to combat the haze will be futile.

Table 4. Spatial effect decomposition results of SDM

\begin{tabular}{ccccc}
\hline \multirow{2}{*}{$\begin{array}{c}\text { explanatory } \\
\text { variables }\end{array}$} & \multicolumn{2}{c}{ domestic tourism flows } & \multicolumn{2}{c}{ inbound tourist flows } \\
\cline { 2 - 5 } & direct effect & $\begin{array}{c}\text { spillover } \\
\text { effect }\end{array}$ & direct effect & $\begin{array}{c}\text { spillover } \\
\text { effect }\end{array}$ \\
\hline LnPm & 0.229 & -0.008 & $-0.124^{* *}$ & $-0.055^{* *}$ \\
LnEco & $0.604^{* * *}$ & $0.256^{*}$ & $0.501^{* * *}$ & $0.289^{*}$ \\
LnRes & $0.221^{* *}$ & -0.158 & $0.220^{*}$ & -0.103 \\
LnTra & $0.239^{* * *}$ & $-0.128^{* * *}$ & $0.109^{* *}$ & -0.168 \\
LnInf & $0.281^{*}$ & $0.175^{*}$ & 0.278 & $0.094^{*}$ \\
LnMar & $0.508^{* * *}$ & $0.312^{*}$ & - & - \\
LnFDI & - & - & $0.402^{* * *}$ & 0.366 \\
\hline
\end{tabular}

Note: ${ }^{* *}, * *$ and $*$ represent significance at the levels of $0.01,0.05$ and 0.10 , respectively.

Control variables, namely economic development factor, market size factor, tourism infrastructure, transportation location factor and tourism resource endowment are arranged in descending order considering their direct effects on domestic tourism flows, with the coefficients of $0.604,0.508,0.281,0.239$, and 0.221 respectively, all of which pass the significance test of at least 0.10 . The economic development factor is also the most critical factor affecting domestic tourism flows. Each $1 \%$ increase in the economic development factor, the market size factor, the tourism infrastructure, the transportation location factor, and the tourism resource endowment of the municipal unit will contribute to an increase of $0.604 \%$, $0.508 \%, 0.281 \%, 0.239 \%$, and $0.221 \%$ respectively, in the domestic tourism flows of the municipal unit. The spatial spillover impacts of each control variable on domestic tourism flows in descending order are market size factor, economic development factor, tourism infrastructure factor, transportation location factor, with spatial spillover coefficients of 0.312 , $0.256,0.175$, and -0.128 respectively, all of which pass the significance level test of at least 0.10. Market size factor, economic development factor, and tourism infrastructure have positive spatial spillover effects. A $1 \%$ positive change in these three variables in the neighboring municipal units will promote the increase of domestic tourism flows in local municipal unit by $0.312 \%, 0.256 \%$, and $0.175 \%$ respectively, while each $1 \%$ positive change in the transportation location factor of the neighboring municipal units will lead to a decrease of $0.128 \%$ in the tourism flows in this municipal unit. The shielding effect caused by improvement in transportation conditions on domestic tourism flows is greater.

As to the decomposition results of the spatial effects of each control variable on inbound tourism flows, the influence of each control variable differs significantly from its impact on domestic tourism flows. Control variables whose direct effects on inbound tourism flows descend are arranged in the order of economic development factor, external linkage, tourism resource endowment, and transportation location factor, with direct effect coefficients of 0.501 , $0.402,0.220$, and 0.109 respectively, all passing the significance test of at least 0.10 . The 
economic development factor is also the most critical factor affecting inbound tourism flows, and it was followed by external linkage. Each $1 \%$ increase in the economic development factor, the external linkage, the tourism resource endowment, and the transportation location factor of this municipal unit will promote the growth of inbound tourism flows of the municipal unit by $0.501 \%, 0.402 \%, 0.220 \%$ and $0.109 \%$ respectively. Among the control variables, only the spatial spillover coefficients of the economic development factor and tourism infrastructure for inbound tourism flows passe the significance level test of 0.10 , at 0.289 and 0.094 respectively, indicating that each $1 \%$ positive change in the economic development factor and tourism infrastructure of the neighboring municipal units will promote $0.289 \%$ and $0.094 \%$ growth in the inbound tourism flows of the local municipal unit. The spatial spillover coefficients of the external linkage, tourism resource endowment, and transportation location factors are $0.366,-0.103$, and -0.168 respectively, all of which do not pass the significance test and are not statistically significant, indicating that the external linkage, tourism infrastructure, tourism resource endowment, and transportation location factors of the neighboring municipal units do not have essential impacts on the growth of inbound tourism in this municipal unit for the time being.

\section{Regional Heterogeneity of Effects}

\subsection{Estimation Results for Eastern, Central, and Western Regions}

Using SDM to estimate the impact of haze pollution on tourism flows, it is found (Table 5) that in the eastern, central, and western regions, SDM is better fitted in the central region on domestic tourism flows with Loglikelihood and adjusted $\mathrm{R}^{2}$ being 90.126 and 0.869 respectively, while on inbound tourism flows SDM is better fitted in the eastern region with Loglikelihood and adjusted $\mathrm{R}^{2}$ being 90.780 and 0.898 respectively. The $\rho$ values of SDM for the impact on domestic tourism flows are $0.495,0.418$, and 0.327 respectively, while for the impact on inbound tourism flows are $0.322,0.294$, and 0.150 respectively. All the $\rho$ values at least pass the significance level test of 0.10 , indicating that there are significant positive spatial spillover effects of both domestic and inbound tourism flows in the eastern, central, and western regions, and the positive spatial spillover intensity of domestic tourism flows is significantly higher than that of inbound tourism flows in all the regions. The results further indicate that both domestic and inbound tourism flows have the highest spatial spillover effect in the eastern region, followed by the central region, and then the western region. Provided that other explanatory variables are controlled, each $1 \%$ increase in domestic tourism flows and inbound tourism flows of the neighboring cities in the eastern, central, and western regions will lead to an increase of $0.495 \%, 0.418 \%$, and $0.327 \%$ in domestic tourism flows and an increase of $0.322 \%, 0.294 \%$, and $0.150 \%$ in inbound tourism flows of local cities respectively.

Table 5. SDM estimation results of the impact of haze pollution in the eastern, middle and western on tourism flows.

\begin{tabular}{cccccccccc}
\hline \multirow{2}{*}{ variable } & \multicolumn{3}{c}{ tourism flows } & \multicolumn{3}{c}{ domestic tourism flows } & \multicolumn{2}{c}{ inbound tourism flows } \\
\cline { 2 - 9 } & eastern & middle & western & eastern & middle & western & eastern & middle & western \\
\hline LnPm & 0.208 & $-0.211^{*}$ & 0.124 & 0.201 & $-0.275^{*}$ & 0.129 & $-0.245^{*}$ & $-0.327^{* *}$ & -0.012 \\
$\mathrm{LnEco}$ & $0.501^{* *}$ & $0.639^{* * *}$ & $0.597^{* *}$ & $0.500^{* *}$ & $0.644^{* * *}$ & $0.586^{*}$ & $0.401^{* * *}$ & $0.578^{* *}$ & $0.555^{* *}$
\end{tabular}




\begin{tabular}{|c|c|c|c|c|c|c|c|c|c|}
\hline LnRes & 0.249 & $0.245^{*}$ & $0.169 * *$ & 0.255 & $0.247^{*}$ & $0.162^{* *}$ & $0.312^{* * *}$ & $0.255^{*}$ & 0.201 \\
\hline LnTra & $0.171^{* *}$ & $0.272 * *$ & $0.311^{*}$ & $0.177^{*}$ & $0.289 * *$ & $0.301 *$ & $0.208^{* *}$ & $0.247^{* *}$ & $0.159 *$ \\
\hline LnInf & $0.198^{* *}$ & $0.326^{*}$ & $0.301 *$ & $0.220^{*}$ & $0.369 *$ & $0.307^{*}$ & $0.321^{* *}$ & 0.301 & 0.224 \\
\hline LnMar & $0.498 * *$ & $0.599 *$ & $0.526^{* *}$ & $0.509^{* *}$ & $0.601^{*}$ & $0.530 * * *$ & - & - & - \\
\hline $\operatorname{LnFDI}$ & $0.196 *$ & 0.101 & 0.128 & - & - & - & $0.475^{* *}$ & $0.401^{*}$ & 0.318 \\
\hline$W \times \operatorname{Ln} P m$ & 0.149 & -0.097 & 0.111 & 0.185 & -0.122 & 0.021 & $-0.072 *$ & $-0.096^{*}$ & -0.007 \\
\hline$W \times \operatorname{Ln} E c o$ & $0.298^{* *}$ & $0.201^{*}$ & 0.006 & $0.300 *$ & $0.245^{* *}$ & 0.024 & $0.275^{*}$ & $0.201^{* *}$ & $0.182^{* *}$ \\
\hline$W \times \operatorname{LnRes}$ & $-0.175^{*}$ & 0.076 & 0.054 & $-0.199 *$ & $0.124 *$ & 0.076 & -0.096 & 0.124 & 0.169 \\
\hline$W \times \operatorname{LnTra}$ & $-0.119 * *$ & -0.086 & $0.121 *$ & $-0.137 * *$ & $-0.067^{*}$ & $0.104 *$ & $-0.189^{*}$ & $0.101^{*}$ & $0.078^{*}$ \\
\hline$W \times \operatorname{Ln} I n f$ & 0.219 & $0.284^{* *}$ & 0.202 & $0.225^{*}$ & $0.298^{* *}$ & 0.201 & $0.175^{* *}$ & $0.204^{*}$ & 0.166 \\
\hline$W \times$ LnMar & $0.274^{* *}$ & $0.398^{* * *}$ & $0.201^{* * *}$ & $0.280^{* *}$ & $0.412 * * *$ & $0.223^{*}$ & - & - & - \\
\hline$W \times \operatorname{Ln} F D I$ & $-0.142 *$ & 0.056 & -0.079 & - & - & - & $0.299 *$ & 0.251 & 0.089 \\
\hline$\rho$ & $0.454^{* * *}$ & $0.407 * * *$ & $0.309 *$ & $0.495^{* *}$ & $0.418 * * *$ & $0.327^{* *}$ & $0.322^{* *}$ & $0.294^{*}$ & $0.150 *$ \\
\hline Adjusted $R^{2}$ & 0.841 & 0.852 & 0.708 & 0.827 & 0.869 & 0.722 & 0.898 & 0.801 & 0.707 \\
\hline Loglikelihood & 90.844 & 93.020 & 78.369 & 92.018 & 90.126 & 79.028 & 90.780 & 89.021 & 74.198 \\
\hline
\end{tabular}

Note: $* * *, * *$ and $*$ represent significance at the levels of $0.01,0.05$ and 0.10 , respectively.

\subsection{Analysis of Differences in Regional Heterogeneity in Estimation Results}

Taking the decomposition results of the spatial impacts of haze pollution on tourism flows in the eastern, central, and western regions (Table 6), haze pollution only has an obvious negative direct effect on tourism flows and domestic tourism flows in the central region, and the direct effect coefficients are -0.203 and -0.255 respectively, indicating that each $1 \%$ increase in haze pollution in the local city in the central region will lead to a decrease of $0.203 \%$ and $0.255 \%$ in the overall tourism flows and domestic tourism flows respectively. In the eastern and central regions, there is an obvious negative direct effect and spatial spillover effect of haze pollution on inbound tourism flows. The coefficients of direct effect and spatial spillover effect in the eastern regions are -0.169 and -0.087 respectively, while the data in the central region are -0.297 and -0.125 respectively, indicating that in the eastern region, each $1 \%$ increase in the level of haze pollution in the local city will lead to a $0.169 \%$ decrease in the inbound tourism flows, while each $1 \%$ increase of the haze pollution in the neighboring city will lead to a $0.087 \%$ decrease in the inbound tourism flows in the local city. In the central regions, a $1 \%$ increase in haze pollution in the local city will lead to a $0.297 \%$ decrease in its inbound tourism flows, while a $1 \%$ increase in neighboring city will lead to a $0.125 \%$ decrease in inbound tourism flows in the local city. In recent years, the central and eastern regions of China have seen a high incidence of haze pollution, coupled with the high sensitivity of inbound tourists to haze. The bad effects of haze pollution on tourism flows in China mainly centered on the inbound tourism in the central and eastern regions, so the treatment and prevention of haze pollution and the creation of a healthy international tourism image become particularly urgent for the regions willing to achieve high-quality tourism development. 
Table 6. Spatial Effect Decomposition Results of SDM in the Eastern, Middle and Western.

\begin{tabular}{|c|c|c|c|c|c|c|c|}
\hline \multirow{3}{*}{$\begin{array}{l}\text { Explanatory } \\
\text { Variables }\end{array}$} & \multirow{3}{*}{ Region } & \multicolumn{2}{|c|}{ Tourism Flows } & \multicolumn{2}{|c|}{$\begin{array}{c}\text { Domestic Tourism } \\
\text { Flows }\end{array}$} & \multicolumn{2}{|c|}{ Inbound Tourism Flows } \\
\hline & & \multirow{2}{*}{ Direct Effect } & Spillover & Direct & Spillover & Direct & Spillover \\
\hline & & & Effect & Effect & Effect & Effect & Effect \\
\hline \multirow{3}{*}{$\mathrm{LnPm}$} & Eastern & 0.234 & 0.125 & 0.209 & 0.168 & $-0.169 *$ & $-0.087^{*}$ \\
\hline & Middle & $-0.203 *$ & -0.084 & $-0.255^{*}$ & -0.134 & $-0.297 * *$ & $-0.125 * * *$ \\
\hline & Western & 0.101 & 0.059 & 0.098 & 0.094 & -0.101 & -0.042 \\
\hline \multirow{3}{*}{ LnEco } & Eastern & $0.551^{* * *}$ & $0.289 * *$ & $0.574 * * *$ & $0.291 * *$ & $0.474 * * *$ & $0.205^{* *}$ \\
\hline & Middle & $0.601 * * *$ & $0.258 * *$ & $0.592 * * *$ & $0.252 * *$ & $0.508 * * *$ & $0.126^{*}$ \\
\hline & Western & $0.475 * * *$ & $0.201^{*}$ & $0.479 * *$ & $0.214^{*}$ & $0.407 * *$ & 0.104 \\
\hline \multirow{3}{*}{ LnRes } & Eastern & $0.222 *$ & $-0.111^{*}$ & $0.231 *$ & $-0.166^{*}$ & $0.279 * *$ & -0.099 \\
\hline & Middle & $0.237 * *$ & -0.146 & $0.247^{* *}$ & -0.179 & $0.289 *$ & 0.125 \\
\hline & Western & $0.201^{*}$ & 0.102 & $0.209 *$ & 0.194 & $0.201^{*}$ & 0.111 \\
\hline \multirow{3}{*}{ LnTra } & Eastern & $0.178^{* *}$ & $-0.184 *$ & $0.182 *$ & $-0.176^{*}$ & $0.147 * *$ & $-0.175^{*}$ \\
\hline & Middle & $0.202^{* * *}$ & -0.129 & $0.209 * * *$ & -0.125 & $0.208^{* *}$ & $0.196^{*}$ \\
\hline & Western & $0.259 * *$ & 0.095 & $0.260^{* *}$ & 0.102 & $0.096^{*}$ & $0.101^{*}$ \\
\hline \multirow{3}{*}{$\operatorname{Ln} I n f$} & Eastern & $0.301^{* *}$ & $0.105^{* *}$ & $0.312^{* * *}$ & $0.107 * *$ & $0.301 *$ & $0.198^{*}$ \\
\hline & Middle & $0.333 * *$ & 0.286 & $0.347 *$ & $0.294 *$ & 0.256 & $0.215^{* *}$ \\
\hline & Western & $0.214^{*}$ & 0.100 & $0.216^{*}$ & 0.105 & 0.201 & 0.154 \\
\hline \multirow{3}{*}{ LnMar } & Eastern & $0.478 * * *$ & $0.301^{* *}$ & $0.479 * * *$ & $0.304 * *$ & - & - \\
\hline & Middle & $0.554 * * *$ & $0.307^{* *}$ & $0.560 * *$ & $0.325 * *$ & 一 & - \\
\hline & Western & $0.402 * *$ & $0.290 * *$ & $0.412 * * *$ & $0.294 *$ & - & - \\
\hline \multirow{3}{*}{$\operatorname{LnFDI}$} & Eastern & $0.185 * *$ & $-0.131 *$ & - & - & $0.387^{*}$ & $0.306^{*}$ \\
\hline & Middle & 0.142 & 0.102 & - & 一 & $0.324 *$ & 0.261 \\
\hline & Western & 0.101 & -0.085 & - & - & 0.240 & 0.085 \\
\hline
\end{tabular}

Note: ***,** and * represent significance at the levels of $0.01,0.05$ and 0.10 , respectively.

The direct and spillover effects of each control variable on tourism flows differ from region to region, coming to the decomposition results of the spatial effects of each control variable (Table 6). Specifically, the positive direct effect coefficients and spatial spillover effect coefficients on both domestic and inbound tourism flows are also significantly positive, with the largest positive direct effect on domestic and inbound tourism flows being in the central regions and the largest spatial spillover effect on domestic and inbound tourism flows being in the eastern regions. Tourism resource endowment has significantly positive direct effects on both domestic and inbound tourism flows in the cities of the eastern, central, and western 
regions. The largest direct effect coefficients on domestic and inbound tourism flows are 0.247 and 0.289 respectively in the central regions, while the smallest direct effect coefficients are 0.209 and 0.201 respectively in the western regions. Tourism resource endowment has significantly negative spatial spillover effects on municipal domestic tourism flows in the cities of the eastern regions, while the spatial spillover effects on the municipal domestic tourism flows in the central and western regions was not significant. The spatial spillover effects on the inbound tourism flows in the eastern, central, and western regions are also not significant. The transportation location factor also has significantly positive direct effect on both domestic and inbound tourism flows in the cities of the eastern, central, and western regions, with the largest direct effect on domestic tourism flows being in the western regions and the largest direct effect coefficient on inbound tourism flows occurring in the central regions. Every $1 \%$ increase in the transportation location factor in the central region will promote a $0.208 \%$ increase in the elasticity of inbound tourism flows in the local city. The spatial spillover impacts of transportation location factor on domestic tourism flows and inbound tourism flows in the eastern regions are significantly negative, and the spatial spillover effects on inbound tourism flows in the central and western regions are significantly positive. Each 1\% increase in the transportation location factor of the neighboring city in the central and western regions will promote a $0.101 \%$ increase in the elasticity of inbound tourism flows in the local city.

\section{Conclusion and Discussion}

The impact of global climate changing and continuous air quality deterioration on tourism markets is increasing. Haze weather has caused a significant impact on tourism that cannot be ignored. However, in the urban area, the impact of haze pollution on tourism flows has not attracted enough attention, and there is a lack of exploration on their possible spatial effects of tourism flows and haze pollution, or on the differences in their action ranges. Therefore, this paper constructs a variety of spatial econometric models of the effects of haze pollution on tourism flows, empirically demonstrates the effects of haze pollution on tourism flows, including domestic and inbound tourism flows, in China's cities from 2001 to 2018, and reveals the regional heterogeneity differences of these effects in eastern, central, and western China. The main contributions of the paper are summarized as follows:

Firstly, the Environmental Kuznets Curve between haze pollution and tourism flows is not significant, and there is an inverted U-shaped relationship between haze pollution and municipal domestic and inbound tourism flows in the eastern and western regions. Secondly, there is a significantly positive spillover effect of tourism flows in the eastern, central, and western regions, and the intensity of spillover is higher for domestic tourism flows than for inbound tourism flows, and the spillover effect of both is greatest in the eastern. Thirdly, in all of the regions, the negative effect of Chinese haze pollution on tourism flows mainly exists in inbound tourism, and haze pollution imposes more prominent negative direct effect on domestic tourism flows in the central region, and there is remarkable negative direct effect and spillover impact on inbound tourism flows in the central and eastern regions.

China already secures a big tourism market, but it is not yet a strong tourism power. The core of building a world tourism power is quality. To enhance the comprehensive competitiveness and international influence of China's tourism, we must actively adopt the coping strategies of tourism development. The following countermeasures are proposed: Firstly, China needs to increase air pollution prevention and control efforts, vigorously promoting and calling for low-carbon lifestyle and business philosophy to strengthen 
environmental education. Secondly, it is wise to establish cross-regional tourism cooperation mechanisms and cross-departmental internal coordination mechanisms, and adopt coping measures of regional joint prevention and control, joint management of departments, and active participation of social forces. Thirdly, develop a system of innovative tourism products and strive to develop emerging tourism industry formats.

Tourism flows have always been the key research direction and core content of tourist cities. However, due to the complex process of urban tourism development, tourism flows are affected by many internal and external factors. Because there are no unified standard or factor index system can be followed academically, this research still has shortcomings and needs to be further improved and deepened. First of all, in terms of research measurement, subsequent studies can start from the internal thrust of tourists and explore the influencing mechanism of haze pollution on tourism flows from the perspectives of per capita GDP, leisure time and tourism motivation of tourists.

Secondly, in terms of research data, we can use different index data, such as air quality index (AQI), and more detailed time-series data, such as a month, a week and a day, to analyze the impact of haze pollution on the tourists flows.

In addition, by digging big data such as online text data and geo-tagged photos, we can also study the impact of haze on tourists' perception and behaviors, so as to discover more general mechanism of haze pollution on tourism flows.

\section{Acknowledgment}

This paper is supported by the National Natural Science Foundation of China (No.41771154). The authors are grateful to the anonymous reviewers whose comments helped to improve this paper.

\section{References}

[1] T. Gan, H. Yang, and W. Liang, "How do urban haze pollution and economic development affect each other? Empirical evidence from 287 Chinese cities during 2000-2016," Sustainable Cities and Society, vol. 65, Feb. 2021. Article (CrossRef Link)

[2] L. Han, W. Zhou, W. Li, and L. Li, "Impact of urbanization level on urban air quality: a case of fine particles PM (2.5) in Chinese cities," Environmental Pollution, vol. 194, pp. 163-170, Nov. 2014. Article (CrossRef Link)

[3] C. K. Chan and X. Yao, "Air pollution in mega cities in China," Atmospheric Environment, vol.42, no. 1, pp. 1-42, Jan. 2008. Article (CrossRef Link)

[4] A. Gani and M. D. Clemes, "The main determinants effecting international visitor arrivals in New Zealand: Some empirical evidence," Tourism Economics, vol. 23, no. 5, pp. 921-940, Jun. 2016. Article (CrossRef Link)

[5] W. Hu and G. Wall, "Environmental Management, Environmental Image and the Competitive Tourist Attraction," Journal of Sustainable Tourism, vol. 13, no. 6, pp. 617-635, Dec. 2008. Article (CrossRef Link)

[6] R. Law and C. Cheung, "Air Quality in Hong Kong: A Study of the Perception of International Visitors," Journal of Sustainable Tourism, vol. 15, no. 4, pp. 390-401, Jan. 2009. Article (CrossRef Link)

[7] T. Mihalic, "Environmental management of a tourist destination: a factor of tourism competitiveness," Tourism Management, vol. 21, no. 1, pp. 65-78, Feb. 2000.

Article (CrossRef Link) 
[8] S. Becken, X. Jin, C. Zhang, and J. Gao, "Urban air pollution in China: destination image and risk perceptions," Journal of Sustainable Tourism, vol. 25, no. 1, pp. 130-147, May. 2016. Article (CrossRef Link)

[9] Y. Zhang, J. H. Xu, and P.J. Zhuang, "The Spatial Relationship of Tourist Distribution in Chinese Cities," Tourism Geographies, vol. 13, no. 1, pp. 75-90, Mar. 2011. Article (CrossRef Link)

[10] N. Gooroochurn and A. Hanley, "Spillover effects in long-haul visitors between two regions," Regional Studies, vol. 39, no. 6, pp. 727-738, Aug. 2010. Article (CrossRef Link)

[11] X. Chen, S. Shao, Z. Tian, Z. Xie, and P. Yin, "Impacts of air pollution and its spatial spillover effect on public health based on China's big data sample," Journal of Cleaner Production, vol. 142, pp. 915-925, Jan. 2017. Article (CrossRef Link)

[12] Y. L. Lu, Y. Wang, W. Zhang, K. Hubacek, F. F. Bi, J. Zuo, H. Q. Jiang, Z. K. Zhang, K. S. Feng, Y. Liu, and W. B. Xue, "Provincial air pollution responsibility and environmental tax of China based on interregional linkage indicators," Journal of Cleaner Production, vol. 235, pp. 337-347, Oct. 2019. Article (CrossRef Link)

[13] A. Zhang, L. Zhong, Y. Xu, H. Wang, and L. Dang, "Tourists' Perception of Haze Pollution and the Potential Impacts on Travel: Reshaping the Features of Tourism Seasonality in Beijing, China," Sustainability, vol. 7, no. 3, pp. 2397-2414, Feb. 2015. Article (CrossRef Link)

[14] T. Deng, X. Li, and M. Ma, "Evaluating impact of air pollution on China’s inbound tourism industry: a spatial econometric approach," Asia Pacific Journal of Tourism Research, vol. 22, no. 7, pp. 771780, Jun. 2017. Article (CrossRef Link)

[15] X. Zhou, Y. Santana Jiménez, J. V. Pérez Rodríguez, and J. M. Hernández, "Air pollution and tourism demand: A case study of Beijing, China," International Journal of Tourism Research, vol. 21, no. 6, pp. 747-757, Jul. 2019. Article (CrossRef Link)

[16] Y. Tao, F. Zhang, C. Shi, and Y. Chen, "Social Media Data-Based Sentiment Analysis of Tourists' Air Quality Perceptions," Sustainability, vol. 11, no. 18, Sept. 2019. Article (CrossRef Link)

[17] J. C. Chow, "Welcome to a Special Issue on PM25: A Fine Particle Standard," Journal of the Air \& Waste Management Association, vol. 49, no. 9, pp. 2-2, Dec. 2011. Article (CrossRef Link)

[18] C. Brokamp, M. B. Rao, Z. Fan, and P. H. Ryan, "Does the elemental composition of indoor and outdoor PM2.5 accurately represent the elemental composition of personal PM2.5?," Atmospheric Environment, vol. 101, pp. 226-234, Jan. 2015. Article (CrossRef Link)

[19] G. Mohammed, G. Karani, and D. Mitchell, "Trace Elemental Composition in PM10 and PM2.5 Collected in Cardiff, Wales," Energy Procedia, vol. 111, pp. 540-547, Mar. 2017. Article (CrossRef Link)

[20] Y. Y. Zhang, J. L. Lang, S. Y. Cheng, S. Y. Li, Y. Zhou, D. S. Chen, H. Y. Zhang, and H. Y. Wang, "Chemical composition and sources of PM1 and PM2.5 in Beijing in autumn," Science of The Total Environment, vol. 630, pp. 72-82, Jul. 2018. Article (CrossRef Link)

[21] A. Trusz, H. Ghazal, and K. Piekarska, "Seasonal variability of chemical composition and mutagenic effect of organic PM2.5 pollutants collected in the urban area of Wroclaw (Poland)," Science of The Total Environment, vol. 733, p. 138911, Sep. 2020. Article (CrossRef Link)

[22] L. Moufarrej, D. Courcot, and F. Ledoux, "Assessment of the PM2.5 oxidative potential in a coastal industrial city in Northern France: Relationships with chemical composition, local emissions and long range sources," Science of The Total Environment, vol. 748, p. 141448, Dec. 2020. Article (CrossRef Link)

[23] Y. H. Zhou, H. Y. Xiao, H. Guan, N. J. Zheng, Z. Y. Zhang, J. Tian, L. L. Qu, J. J. Zhao, and H. W. Xiao, "Chemical composition and seasonal variations of PM2.5 in an urban environment in Kunming, SW China: Importance of prevailing westernerlies in cold season," Atmospheric Environment, vol. 237, Sept. 2020.

[24] Y. Yu, F. Ding, Y. Mu, M. Xie, and Q. Wang, "High time-resolved PM2.5 composition and sources at an urban site in Yangtze River Delta, China after the implementation of the APPCAP," Chemosphere, vol. 261, p. 127746, Dec. 2020. Article (CrossRef Link)

[25] P. Pakbin, N. Hudda, K. L. Cheung, K. F. Moore, and C. Sioutas, "Spatial and Temporal Variability of Coarse ( $\mathrm{PM}_{10-2.5)}$ Particulate Matter Concentrations in the Los Angeles Area," Aerosol Science and Technology, vol. 44, no. 7, pp. 514-525, Jun. 2010. Article (CrossRef Link) 
[26] P. S. Zhao, F. Dong, D. He, X. J. Zhao, X. L. Zhang, W. Z. Zhang, Q. Yao, and H. Y. Liu, " Characteristics of concentrations and chemical compositions for PM2.5 in the region of Beijing, Tianjin, and Hebei, China," Atmospheric Chemistry and Physics, vol. 13, no. 9, pp. 4631-4644, 2013. Article (CrossRef Link)

[27] J. Poon, I. Casas, and C. He, "The Impact of Energy, Transport, and Trade on Air Pollution in China," Eurasian Geography and Economics, vol. 47, no. 5, pp. 568-584, May. 2013. Article (CrossRef Link)

[28] O. Eitan, Yuval, M. Barchana, J. Dubnov, S. Linn, Y. Carmel, and D. M. Broday, "Spatial analysis of air pollution and cancer incidence rates in Haifa Bay, Israel," Science of The Total Environment, vol. 408, no. 20, pp. 4429-4439, Sep. 2010. Article (CrossRef Link)

[29] M. Lippmann, "Toxicological and epidemiological studies of cardiovascular effects of ambient air fine particulate matter (PM2.5) and its chemical components: Coherence and public health implications," Critical Reviews in Toxicology, vol. 44, no. 4, pp. 299-347, Feb. 2014. Article (CrossRef Link)

[30] A. Bigano, J. M. Hamilton, and R. S. J. Tol, "The Impact of Climate on Holiday Destination Choice," Climatic Change, vol. 76, no. 3, pp. 389-406, Mar. 2006. Article (CrossRef Link)

[31] J. L. Eugenio-Martin and J. A. Campos-Soria, "Climate in the region of origin and destination choice in outbound tourism demand," Tourism Management, vol. 31, no. 6, pp. 744-753, Dec. 2010. Article (CrossRef Link)

[32] R. Buckley, "20 answers: Reconciling air travel and climate change," Annals of Tourism Research, vol. 38, no. 3, pp. 1178-1181, Jul. 2011. Article (CrossRef Link)

[33] M. Berrittella, A. Bigano, R. Roson, and R. S. J. Tol, "A general equilibrium analysis of climate change impacts on tourism," Tourism Management, vol. 27, no. 5, pp. 913-924, Oct. 2006.

[34] C. Chen, Y. Lin, Y. Zhang, C. Hsu, "Does air pollution drive away tourists? A case study of the Sun Moon Lake National Scenic Area, Taiwan," Transportation Research Part D: Transport and Environment, vol. 53, pp. 398- 402, May. 2017. Article (CrossRef Link)

[35] M. Robaina, M. Madaleno, S. Silva, C. Eusébio, M. J. Carneiro, C. Gama, K. Oliveira, M. A. Russo, and A. Monteiro, "The relationship between tourism and air quality in five European countries," Economic Analysis and Policy, vol. 67, pp. 261-272, Aug.2020. Article (CrossRef Link)

[36] D. Dong, X. Xu, H. Yu, and Y. Zhao, "The Impact of Air Pollution on Domestic Tourism in China: A Spatial Econometric Analysis," Sustainability, vol. 11, no. 15, Aug.2019. Article (CrossRef Link)

[37] K. Anaman and C. Looi, "Economic Impact of Haze-Related Air Pollution on the Tourism Industry in Brunei Darussalam," Economic Analysis and Policy, vol. 30, no. 2, pp. 133-143, Sept. 2000. Article (CrossRef Link)

[38] J. Tang, X. Yuan, V. Ramos, and S. Sriboonchitta, "Does air pollution decrease inbound tourist arrivals? The case of Beijing," Asia Pacific Journal of Tourism Research, vol. 24, no. 6, pp. 597605, Apr. 2019. Article (CrossRef Link)

[39] D. Xu, Z. Huang, G. Hou, and C. Zhang, "The spatial spillover effects of haze pollution on inbound tourism: evidence from mid-easternern China," Tourism Geographies, vol. 22, no. 1, pp. 83-104, May. 2019. Article (CrossRef Link)

[40] X. Zhang, Y. Yang, Y. Zhang, and Z. Zhang, "Designing tourist experiences amidst air pollution: A spatial analytical approach using social media," Annals of Tourism Research, vol. 84, Juy.2020. Article (CrossRef Link)

[41] J. P. Elhorst, "Specification and Estimation of Spatial Panel Data Models," International Regional Science Review, vol. 26, no. 3, pp. 244-268, Jul. 2003. Article (CrossRef Link)

[42] J. P. Elhorst, "Applied Spatial Econometrics: Raising the Bar," Spatial Economic Analysis, vol. 5, no. 1, pp. 9-28, Mar. 2010. Article (CrossRef Link)

[43] M. Cole, A. Rayner, J. M. Bates, "The environmental Kuznets curve: an empirical analysis," Environment and Development Economics, vol. 2, no. 4, pp. 401-416, Nov.1997. Article (CrossRef Link)

[44] J.P. Lesage and R.K. Pace, Introduction to Spatial Econometrics, Boca Raton, FL, USA: CRC Press, 2009. 
[45] S. K. Mitra, M. Chattopadhyay, and R. K. Jana, "Spillover analysis of tourist movements within Europe," Annals of Tourism Research, vol. 79, pp. 102754, Nov. 2019. Article (CrossRef Link)

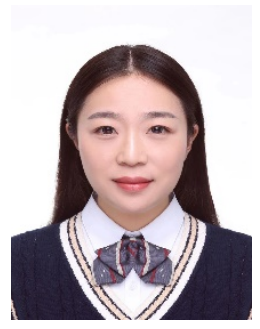

Fangfang Gu is currently pursuing the Ph.D. degree in Management Science and Engineering at Nanjing University of Aeronautics and Astronautics, Nanjing, China. Her research interest includes Tourism Management, Tourism Economics and Tourism Big Data.

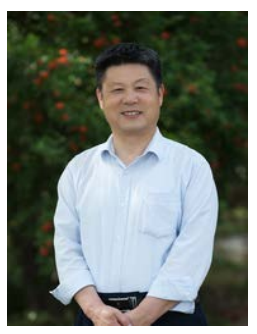

Keshen Jiang is a professor of College of Economics and Management, Nanjing University of Aeronautics and Astronautics, Nanjing, China. His research interest includes Regional Economics and Tourism Economics.

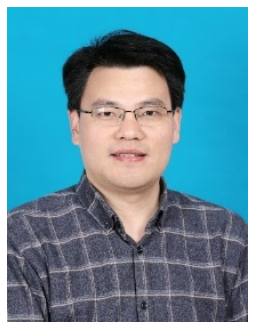

Fangdong Cao received his Ph.D. degree in 2013 from School of Geography, Nanjing Normal University, Nanjing, China. He was promoted as an Associate Professor in Nanjing Normal University in 2016. His research interests include Tourism Economics, Tourism Geography and Data Mining and Tourism Flows. 